\title{
Cellular properties of the fermented microalgae Pavlova lutheri and its isolated active peptide in osteoblastic differentiation of MG-63 cells
}

\author{
ZHONG-JI QIAN $^{1 *}$, BOMI RYU ${ }^{2 *}$, KYONG-HWAKANG $^{3}$, SOO-JIN HEO ${ }^{4}$, DO-HYUNG KANG ${ }^{4}$, \\ SUNG YONG BAE ${ }^{5}$, SUN-JOO PARK ${ }^{6}$, JAE-IL KIM ${ }^{7}$, YOUNG-MOG KIM ${ }^{8}$, \\ YONG-TAE KIM $^{9}$ and WON-KYO JUNG ${ }^{10}$
}

\footnotetext{
${ }^{1}$ Key Laboratory of Advanced Processing of Aquatic Products of Guangdong Higher Education Institution, College of Food Science and Technology, Guangdong Ocean University, Zhanjiang, Guangdong 524088, P.R. China;

${ }^{2}$ School of Pharmacy, The University of Queensland, Brisbane, QLD 4072, Australia;

${ }^{3}$ Marine Bioprocess Research Center, Pukyong National University, Busan 48513;

${ }^{4}$ Jeju International Marine Science Center for Research and Education, Korea Institute of Ocean Science and Technology, Jeju 63349; Departments of ${ }^{5} \mathrm{Naval}$ Architecture and Marine Systems Engineering, ${ }^{6}$ Chemistry,

${ }^{7}$ Food Science and Nutrition, and ${ }^{8}$ Food Science and Technology, Pukyong National University, Busan 48513;

${ }^{9}$ Department of Food Science and Biotechnology, Kunsan National University, Kunsan, North Jeolla 573-701;

${ }^{10}$ Department of Biomedical Engineering, and Center for Marine-Integrated Biomedical Technology (BK21 Plus) and Marine-Integrated Bionics Research Center, Pukyong National University, Busan 48513, Republic of Korea
}

Received July 5, 2017; Accepted November 7, 2017

DOI: $10.3892 / \mathrm{mmr} .2017 .8087$

\begin{abstract}
Fermented microalgae Pavlova lutheri (P. lutheri), the product of Hansenula polymorpha fermentation, exhibited an increase in alkaline phosphatase (ALP) activity in MG-63 osteoblastic cells when compared to that of non-fermented $P$. lutheri. Fractionation of the fermented $P$. lutheri resulted in identification of the active peptide [peptide of $P$. lutheri fermentation (PPLF)] with the sequence of EPQWFL. PPLF significantly increased ALP release from MG-63 cells and mineralization in a dose-dependent manner. In addition, the intracellular levels of ALP and osteocalcin (OCN) proteins were augmented by PPLF treatment. To identify the molecular mechanism underlying the effect of PPLF on osteoblastic differentiation, the phosphorylation levels of the mitogen-activated protein kinases, p38, extracellular signal-regulated kinases $1 / 2$ and Jun, and nuclear factor
\end{abstract}

Correspondence to: Professor Won-Kyo Jung, Department of Biomedical Engineering, and Center for Marine-Integrated Biomedical Technology (BK21 Plus) and Marine-Integrated Bionics Research Center, Pukyong National University, 45 Yongso-ro, Nam-Gu, Busan 48513, Republic of Korea

E-mail: wkjung@pknu.ac.kr

${ }^{*}$ Contributed equally

Key words: peptide, fermented microalgae Pavlova lutheri, osteoblastic differentiation
(NF)- $\mathrm{KB}$ were determined following PPLF treatment and the differences in expression were analyzed using p38 and NF- $\mathrm{KB}$ selective inhibitors. These results concluded that PPLF from fermented $P$. lutheri induced osteoblastic differentiation by increasing ALP and OCN release in MG-63 cells via the p38/p65 signaling pathway, indicating that PPLF supplement may be effective for therapeutic application in the field of bone health.

\section{Introduction}

For a long time, microbial fermentation was applied in milk, soybean, fruit and grain as source of enzymes as a means to provide palatability, nutritional value, preservative and medicinal properties (1). Protein fermentation that mainly occurs through hydrolysis by digestive, microbial, and plant proteolytic enzymes can release the bioactive peptides corresponding to cryptic sequences from native proteins (2-4). Also, the degree of proteolysis depends on the microbial strain used for fermentation and is reported to be directly related to the biological activity of the released peptides (5).

Marine microalgae have been of interest as a biofuel source with their large biomass in the marine environment and recently reported in various studies in the field of pharmaceuticals and nutraceuticals as unconventional protein source (6). We have previously suggested that the fermented of Pavlova lutheri (P. lutheri; microalgae) by Hansenula polymorpha or Candida rugopelliculosa as protein source has potential antioxidant activity via reduction of hydroxyl radical or the increment of antioxidant related enzymes at protein levels in hydroxyl radical-induced oxidative stress (7). 
Bone structure is maintained by upholding a balance between bone formation by osteoblasts and bone resorption by osteoclasts (8-10). Osteoblasts originating from mesenchymal stem cells (MSCs) can translate mechanical signals into biological responses to regulate bone remodelling in intact bone in the process of bone repair (11). The mechanical signal in the cells involves the sequential activation (via phosphorylation cascade) of various intracellular signalling molecules, including MAPKs and phosphoinositide 3-kinase (PI3k)/Akt, resulting in the activation of transcription factors such as activator protein-1 (AP-1) and nuclear factor (NF)- $\kappa \mathrm{B}$ and subsequent modulation of the expression of genes that regulate osteoblast maturation and mineralisation (12-17). The cellular responses in osteoblasts have influence on the interaction between various systemic factors, such as alkaline phosphatase (ALP), bone morphogenetic proteins (BMPs), osteocalcin $(\mathrm{OCN})$, collagen type I ( $\mathrm{Col} \mathrm{I})$ that are generally considered stimulants for osteoblast adhesion and differentiation $(9,18)$.

In the present study, the effect of the $P$. lutheri fermentation on osteoblastic differentiation in MG-63 osteoblastic cells was compared with the non-ferment. The active peptide [peptide of $P$. lutheri fermentation (PPLF)] responsible for the effect was subsequently purified and the mechanism by which PPLF is involved in the regulation of osteoblastic differentiation of MG-63 cells was explored.

\section{Materials and methods}

General. In the previous study, we fermented microalgae Pavlova lutheri by $H$. polymorpha as below (7). The cellulose-degraded microalga $P$. lutheri was autoclaved at $121^{\circ} \mathrm{C}$ for $30 \mathrm{~min}$ in a buffer $(\mathrm{pH} 7)$ solution at a ratio of 1:15 (w/v). Subsequently, $H$. polymorpha was inoculated with the autoclaved solution at a concentration of $1 \%(\mathrm{v} / \mathrm{v})$ and incubated at $37^{\circ} \mathrm{C}$ for 12 days. Fermented microalgae was lyophilized and stored at $80^{\circ} \mathrm{C}$ until used. Human osteoblastic (MG-63) cells were obtained from American Type Culture Collection (Manassas, VA, USA). Dulbecco's Modified Eagle's Medium (DMEM), Trypsin-ethylenediaminetetraacetic acid (EDTA), penicillin/streptomycin, fetal bovine serum (FBS) and other materials required for culturing cells were purchased from Gibco BRL, Life Technologies (Grand Island, NY, USA). The p38 inhibitor (SB203580), NF- $\kappa$ B inhibitor [pyrrolidine dithiocarbamate (PDTC)] and 3-(4,5-dimethyl-2-yl)-2,5-diphenyltetrazolium bromide (MTT) reagent were purchased from Sigma-Aldrich (St. Louis, MO, USA). All other chemicals and reagents used in this study were of analytical grade.

Cell culture and viability assay. Human osteoblastic MG-63 cells were cultured in DMEM containing 5\% FBS in a humidified atmosphere with $5 \% \mathrm{CO}_{2}$ at $37^{\circ} \mathrm{C}$. Cells were sub-cultured at 3-day intervals using trypsin-EDTA and were seeded in 96-well plates at a density of $5 \times 10^{3}$ cells per well. 24 h post plating, media was replaced with DMEM without serum and cells were subjected to sample treatment for another 3 days. Subsequently, $100 \mu \mathrm{l}$ of $1 \mathrm{mg} / \mathrm{ml}$ MTT reagent was added to each well, and incubated for $3 \mathrm{~h}$. The supernatant was removed and formazan was dissolved in DMSO and its formation was observed by monitoring the signal at $540 \mathrm{~nm}$ using a microplate reader.
ALP activity assay. Cells were seeded into 12-well plates at a density of $5 \times 10^{5}$ cells per well for $24 \mathrm{~h}$ and then treated with samples in DMEM media without serum for 3 days. Cells were then washed three times with PBS, and were lysed with a lysis buffer containing $20 \mathrm{mM}$ Tris- $\mathrm{HCl}(\mathrm{pH} 7.5), 150 \mathrm{mM}$ $\mathrm{NaCl}$ and $1 \%$ Triton X-100. Briefly, the lysate was mixed with p-NPP substrate solution which consists of $1.5 \mathrm{mM} \mathrm{MgCl}_{2}$ and $15 \mathrm{mM}$ p-nitrophenyl phosphate (p-NPP). The activity of phosphatases to catalyze the hydrolysis of p-NPP to p-nitrophenol was evaluated by measuring the absorbance at $405 \mathrm{~nm}$ (19). ALP activity was normalized according to the cellular total protein content of cell lysate determined by BCA protein assay (Sigma-Aldrich).

Preparation of fermented microalgae peptide. The lyophilized fermented microalgae was dissolved in distilled water and passed through disposable Silica-based bonded-phase cartridges (Sep-Pak Vac $\mathrm{C}_{18} 20 \mathrm{cc} / 5 \mathrm{~g}$; Waters, Milford, MA, USA). The cartridges were activated with $100 \%$ methanol in $0.1 \%$ trifluoroacetic acid (TFA) and subsequently the cleaned product was eluted with $10 \%$ methanol in $0.1 \%$ TFA. The eluent was lyophilized then further purified as described below.

Purification procedures. The cleaned eluent from previous step was loaded onto HiPrep 16/10 DEAE ion exchange column equilibrated with $20 \mathrm{mM}$ sodium acetate buffer ( $\mathrm{pH} 4.0)$ and eluted with a linear gradient of $\mathrm{NaCl}(0-2 \mathrm{M})$ at a flow rate of $1.0 \mathrm{ml} / \mathrm{min}$ by $280 \mathrm{~nm}$ absorbance using FPLC (Amersham Bioscience Co., Uppsala, Sweden). Separated fractions were pooled and desalted by an electrodialyzer (Micro Acilyzer model G3; Asahi Chemical Industry Co., Tokyo, Japan) with a 100 Da molecular mass cutoff membrane (Asahi Chemical Industry Co.). The desalted fractions were lyophilized and investigated for their ALP activity. The fraction which had the highest ALP activity was further purified on a Primesphere $10 \mathrm{C}_{18}(20 \times 250 \mathrm{~mm})$ column at reversed-phase HPLC (Dionex Corp., Sunnyvale, CA, USA) with a linear gradient of acetonitrile (0-30\% in $30 \mathrm{~min})$ containing $0.1 \%$ TFA at a flow rate $1.0 \mathrm{ml} / \mathrm{min}$ by $215 \mathrm{~nm}$ absorbance. Elution peaks were collected and tested for ALP activity. The highest active fraction was re-applied to a Acclaim $120 \mathrm{C}_{18}$ analytical column with $15 \%$ acetonitrile (20\% v/v, in $15 \mathrm{~min}$ ) containing $0.1 \%$ TFA at flow rate of $1 \mathrm{ml} / \mathrm{min}$. The purified peptide was subjected to amino acid sequence analysis.

Amino acid sequence of the purified peptide. The accurate molecular mass and amino acid sequence of the purified peptide was determined by quadrupole time-of-flight mass spectroscopy (Q-TOF MS; Micromass UK Ltd., Altrincham, UK) coupled to electrospray ionization (ESI) source. The molecular weight of the purified peptide dissolved in methanol/water (1:1, vol/vol) was detected by a doubly charged $(\mathrm{M}+2 \mathrm{H})^{+2}$ state in the mass spectrum and the amino acid sequence was identified by tandem MS analysis. Spray voltage was $4,000 \mathrm{~V}$ and nitrogen was maintained at 40 psi for nebulization. Mass spectra were acquired over the range from 50 to $1,500 \mathrm{~m} / \mathrm{z}$.

Mineralization assay. The levels of mineralization were determined in the 24-well plates using Alizarin Red staining 

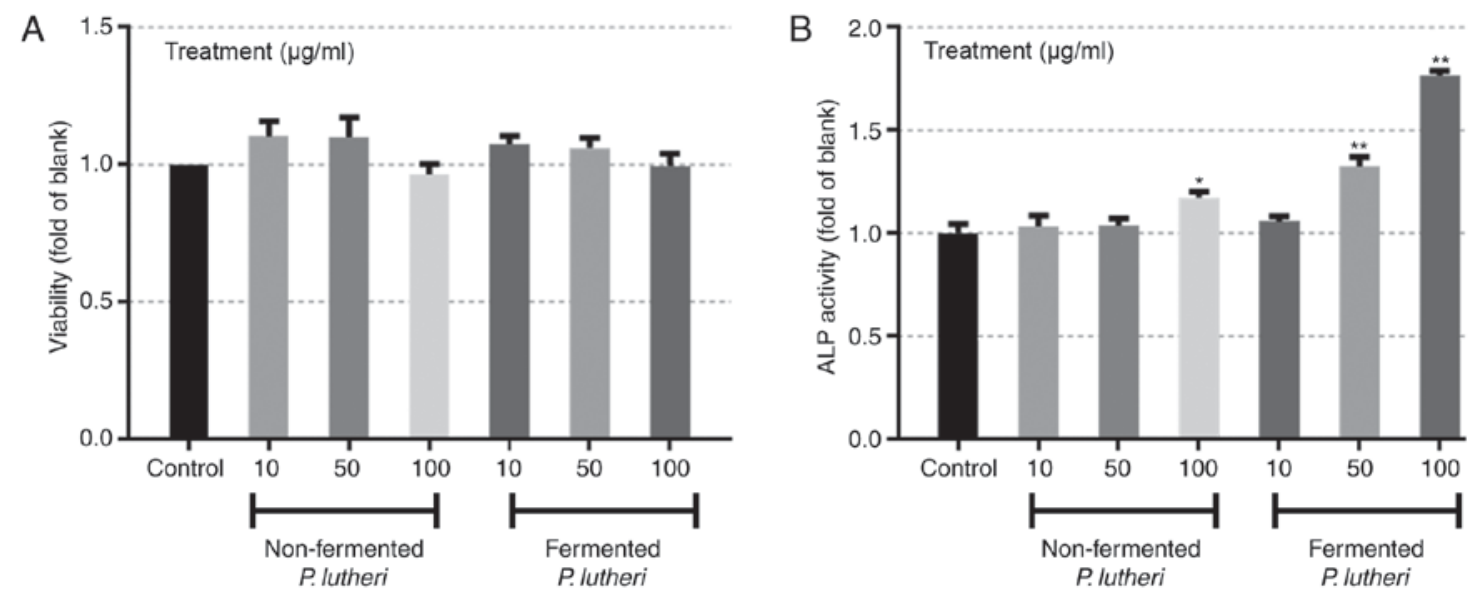

Figure 1. Effects of the non-fermented and fermented P. lutheri on (A) cell viability and (B) ALP activity in MG-63 cells. Cells were cultured with different concentrations of either fermented or non-fermented P. lutheri (10,50 and $100 \mu \mathrm{g} / \mathrm{ml}$ ) for 3 days and analyzed by MTT and ALP assays. Results were normalized to the control groups, which were incubated in Dulbecco's modified Eagle's media without treatment. ${ }^{*} \mathrm{P}<0.05$ and ${ }^{* *} \mathrm{P}<0.01$ vs. control. P. lutheri, Pavlova lutheri; ALP, alkaline phosphatase; MTT, 3-(4,5-dimethyl-2-yl)-2,5-diphenyltetrazolium bromide.

(Sigma-Aldrich) after 7 days treatment with the peptide. Briefly, cells were fixed with $70 \%(\mathrm{v} / \mathrm{v})$ ethanol for $1 \mathrm{~h}$ and then stained with $40 \mathrm{mM}$ Alizarin Red S (pH 4.2) for $15 \mathrm{~min}$ at room temperature. After removing Alizarin Red S solution by aspiration, cells were incubated in PBS for $15 \mathrm{~min}$ at room temperature on an orbital rotator. Cells were then rinsed once with fresh PBS and subsequently distained for $15 \mathrm{~min}$ with $10 \%$ cetylpyridinium chloride in $10 \mathrm{mM}$ sodium phosphate (pH 7.0). The extracted stain was then transferred to a 96-well plate and the absorbance at $562 \mathrm{~nm}$ was measured using a microplate reader (Tecan Austria GmbH, Grödje, Austria).

Western blot analysis. Cells were treated with p38 inhibitor (SB203580, $20 \mu \mathrm{M}$ ) or NF- $\kappa B$ inhibitor (PDTC, $10 \mu \mathrm{M}$ ) for $1 \mathrm{~h}$ prior to treatment with the peptide (in the presence of inhibitor) for $72 \mathrm{~h}$. Cells were then harvested in lysis buffer (RIPA; Sigma-Aldrich). Cleared total cell lysates $(20 \mu \mathrm{g})$ were separated by $10 \%$ SDS-polyacrylamide gel electrophoresis and transferred onto a polyvinylidene fluoride membrane (Amersham Pharmacia Biotech, Amersham, UK). Membrane was blocked with 5\% skim milk and probed with the primary antibody (diluted 1:1,000) followed by incubation with a secondary antibody conjugated with horseradish peroxidase (diluted 1:5,000) at room temperature. The proteins of interest were detected using a chemiluminescent ECL assay kit (Amersham Pharmacia Biotech) according to the manufacturer's instructions. Primary and secondary antibodies including ALP (sc-373737), OCN (sc-365797), $\beta$-actin (sc-47778), p-p38 (sc-7973), p-pERK (sc-7383), p-Jun (sc-822), p-p65 (sc-166748) and anti-mouse IgG-HRP (7076) purchased from Santa Cruz Biotechnology Inc. (Santa Cruz, CA, USA) and Cell Signaling Technology, Inc. (Danvers, MA, USA). Western blots were visualized using an LAS3000 ${ }^{\circledR}$ Luminescent image analyzer and protein expression was quantified by Multi Gauge v3.0 software (Fujifilm Life Science, Tokyo, Japan).

Statistical analysis. All experiments were repeated at least three times and expressed as the means $\pm \mathrm{SD}$. Differences between the means of individual groups were assessed by two-way ANOVA with Tukey's multiple comparisons test using the statistical software package GraphPad Prism 6 software (San Diego, CA, USA).

\section{Results}

Comparison of the ALP activities of fermented and non-fermented $P$. lutheri. We previously investigated the antioxidant activities of the fermented $P$. lutheri microalgae by H.polymorpha or C.rugopelliculosa and suggested the potential of fermented $P$. lutheri as protein source possessing antioxidant activity (7). In this study, we investigated the difference between the effect of fermented and non-fermented $P$. lutheri on osteoblastic differentiation in MG-63 cells. The lyophilized P. lutheri was treated with cellulose ( $1 \%$ dry powder weight of the raw substance) to break its cell wall and was subsequently fermented by inoculation with $H$. polymorpha for 12 days (7). Different concentrations $(10,50,100 \mu \mathrm{g} / \mathrm{ml})$ of fermented and non-fermented P. lutheri (with degraded cell-wall) were added to the cells for 3 days followed by measuring their toxicity and ALP activity. The cells treated with either fermented or non-fermented $P$. lutheri did not show any significant difference in viability compared to control which is non-treatment group (Fig. 1A), however a significant increase in the ALP activity of the cells were observed when treated with $100 \mu \mathrm{g} / \mathrm{ml}$ non-fermented P. lutheri with $\mathrm{P}<0.05$ and 50 and $100 \mu \mathrm{g} / \mathrm{ml}$ fermented P. lutheri with $\mathrm{P}<0.01$ (Fig. 1B).

We then further traced the purification profile of peptide from fermented $P$. lutheri and characterized the effect on osteoblastic differentiation in MG-63 cells.

Fractionation profile of fermented P. lutheri and the effect on ALP activity. The lyophilized fermented P. lutheri was dissolved in distilled water and passed through disposable Sep-Pak Vac $\mathrm{C}_{18}$ cartridges to salt out. The cleaned product was then concentrated and further separated using a weak anion exchange chromatographic method on a FPLC at $280 \mathrm{~nm}$. The monitored peaks were desalted and analyzed for their ALP activity (data not shown). The selected fraction with highest ALP activity was split to four portions through reversed-phase chromatographic method on a HPLC at $215 \mathrm{~nm}$ (Fig. 2A). Each portion was 

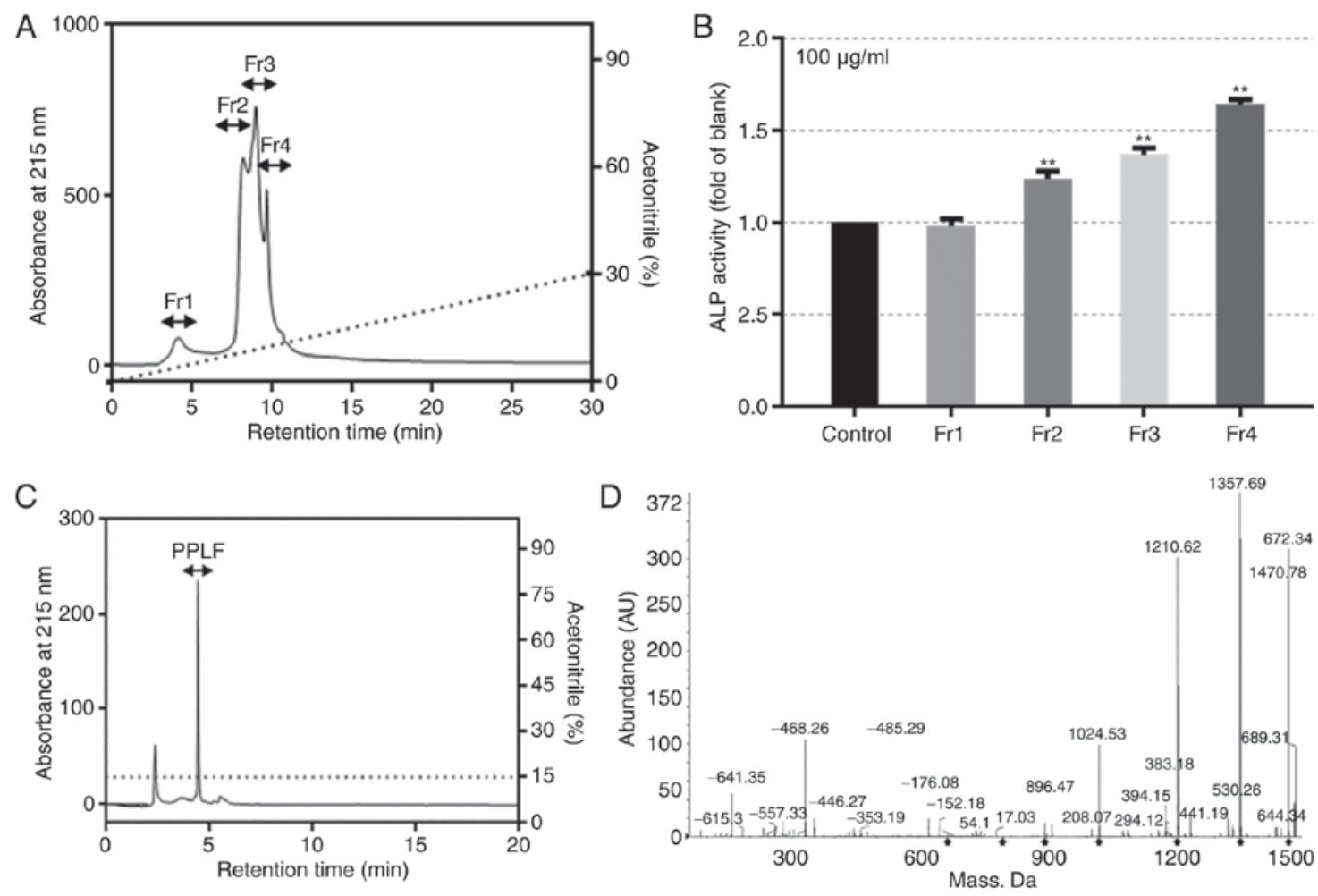

Figure 2. Fractionation of fermented Pavlova lutheri using chromatographic methods and isolation of an active peptide. (A) Fractions from the reversed-phase separation of the fermented product were incubated at a $100 \mu \mathrm{g} / \mathrm{ml}$ concentration with cells for 3 days and their (B) ALP activity was measured. ALP activity was normalized to the control group. ${ }^{* *} \mathrm{P}<0.01$ vs. control. Fraction 4 (Fr. 4) was selected based on its ALP activity, and (C) was reanalyzed and (D) identified as Glu-Pro-Gln-Trp-Phe-Leu (MW 908.9 Da) by electrospray ionization/mass spectroscopy. ALP, alkaline phosphatase; PPLF, peptide of Pavlova lutheri fermentation.
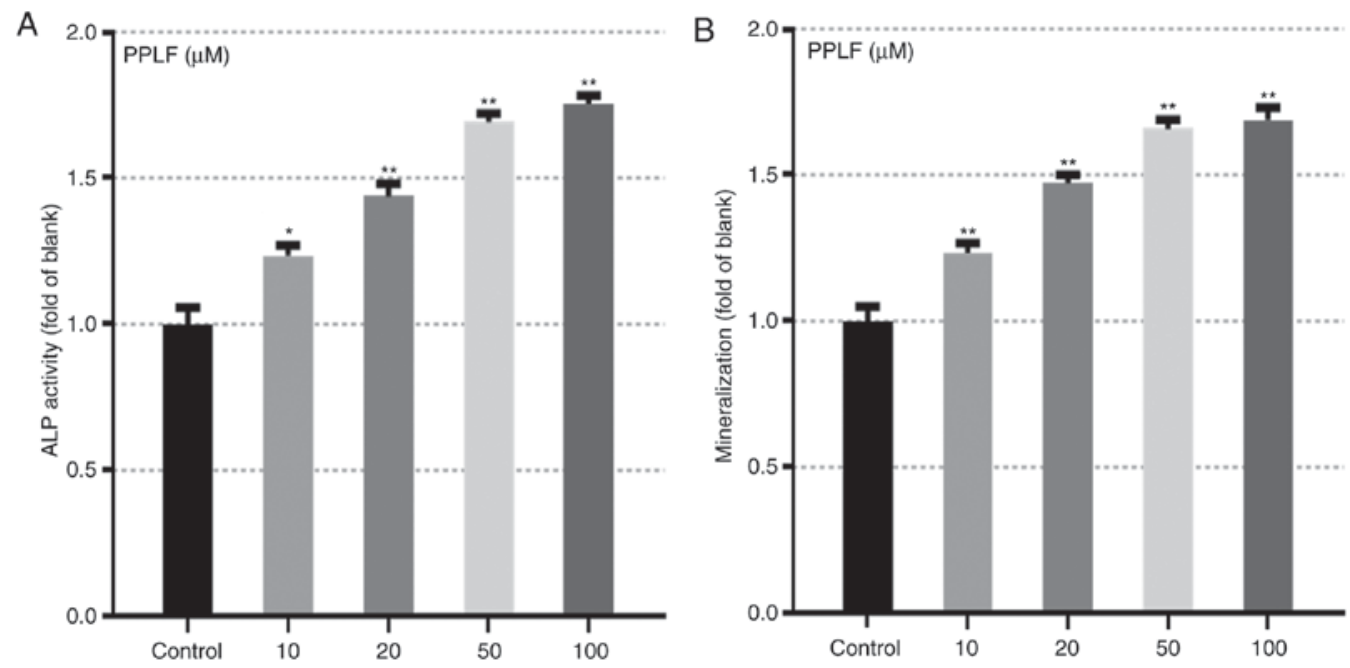

Figure 3. Effects of the purified peptide (PPLF) on (A) ALP activity and (B) mineralization in MG-63 cells. Cells were treated with different concentrations of PPLF $(10,20,50$ and $100 \mu \mathrm{M})$ and measured for their ALP activity at day 3 and mineralization at day 7 . The results were normalized to the control groups. ${ }^{*} \mathrm{P}<0.05$ and ${ }^{* *} \mathrm{P}<0.01$ vs. control. PPLF, peptide of Pavlova lutheri fermentation; ALP, alkaline phosphatase.

measured for its ALP activity at $100 \mu \mathrm{g} / \mathrm{ml}$ and Fraction 4 (Fr.4) showed the highest activity with of 1.642 fold compared to the control (P<0.01; Fig. 2B). The peptide PPLF was purified from the additional analysis using an Acclaim $120 \mathrm{C}_{18}$ analytical column and was determined as Glu-Pro-Gln-Trp-Phe-Leu (MW 908.9 Da) by ESI/MS spectroscopy (Fig. 2C and D).

PPLF peptide prompted the markers for differentiation. The effect of PPLF on ALP activity and mineralization which are main makers for osteoblastic differentiation $(8,18)$ was assessed in MG-63 cells. Cells treated with PPLF showed significantly increased levels of ALP release (Fig. 3A) and mineralization $(\mathrm{P}<0.05$ and $\mathrm{P}<0.01)$ (Fig. $3 \mathrm{~B})$. In order to further assess the effects of PPLF, we analyzed protein levels of two of the known early markers of differentiation ALP and OCN in cells treated with PPLF $(10,20,50 \mu \mathrm{M})$ for 3 days. Both protein levels showed to be up-regulated by PPLF treatment compared to the non-treated cells $(\mathrm{P}<0.05$; Fig. 4). These 

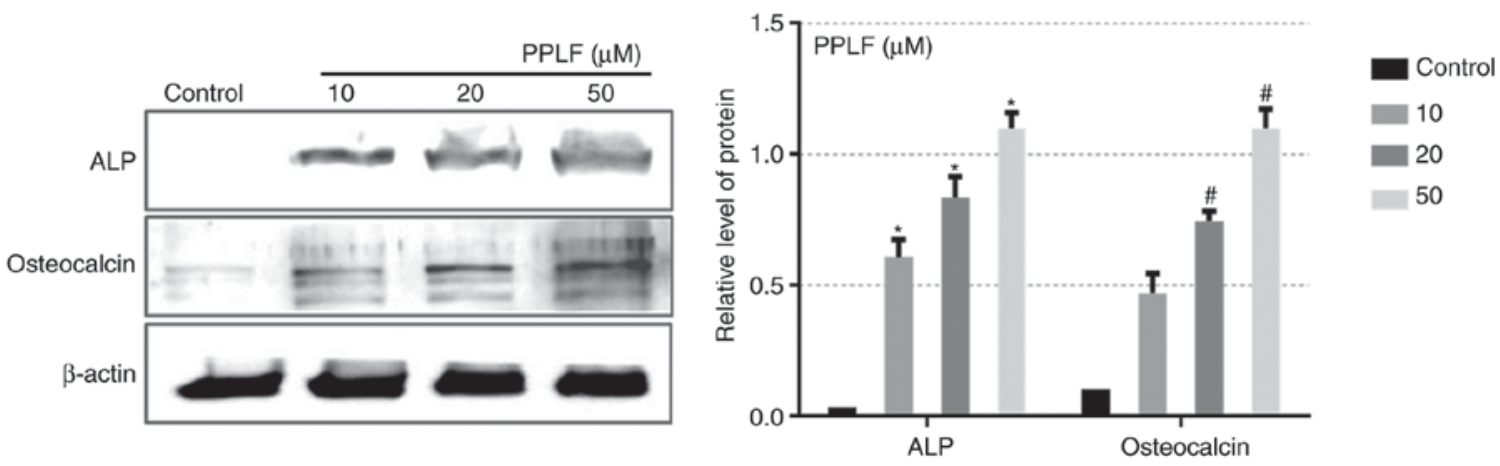

Figure 4. Effects of PPLF on the protein levels of ALP and osteocalcin in MG-63 cells. Cells were incubated with PPLF (10, 20 and $50 \mu \mathrm{M})$ for 3 days, then the protein levels of ALP and osteocalcin were assessed by western blotting. The results were then normalized to $\beta$-actin. ${ }^{*} \mathrm{P}<0.05$ vs. ALP control; ${ }^{*} \mathrm{P}<0.05$ vs. osteocalcin control. PPLF, peptide of Pavlova lutheri fermentation; ALP, alkaline phosphatase.
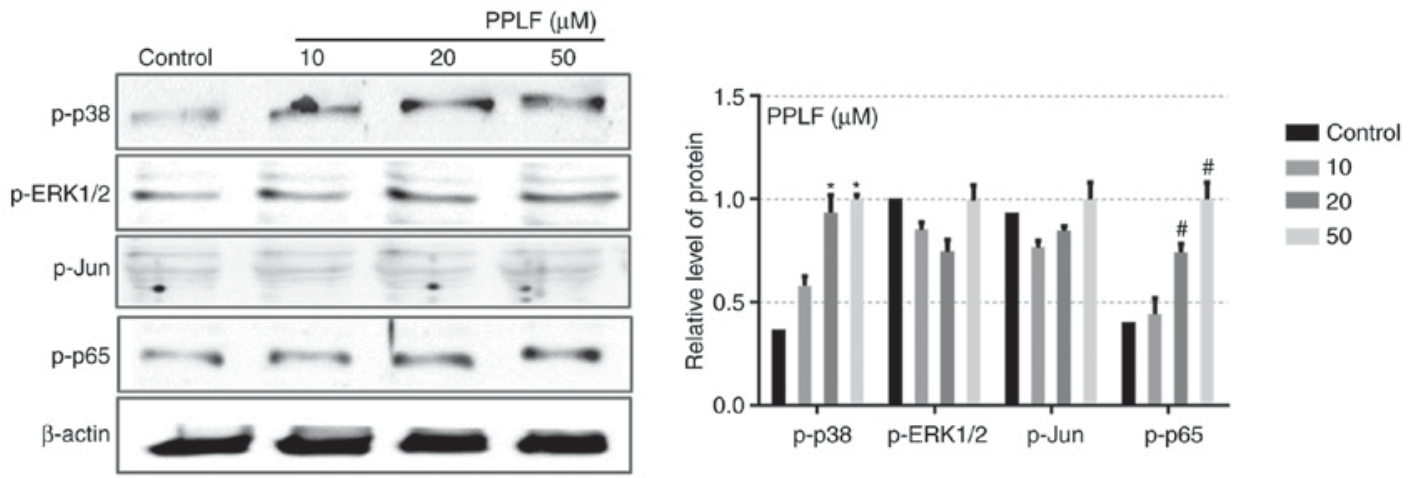

Figure 5. Phosphorylation levels of the three major types of mitogen-associated protein kinases, p38, ERK1/2 and Jun, and NF- $\mathrm{kB}$ (p65) following PPLF treatment in MG-63 cells. Cells were treated with PPLF $(10,20$ and $50 \mu \mathrm{M})$ for 3 days and the levels of p-p38, p-ERK1/2, p-Jun and p-p65 were assessed by western blotting. The results were normalized to $\beta$-actin. ${ }^{*} \mathrm{P}<0.05$ vs. p-p38 control; ${ }^{*} \mathrm{P}<0.05$ vs. p-p65 control. PPLF, peptide of Pavlova lutheri fermentation; ALP, alkaline phosphatase; ERK, extracellular signal-regulated kinase; NF, nuclear factor; p-, phosphorylated.
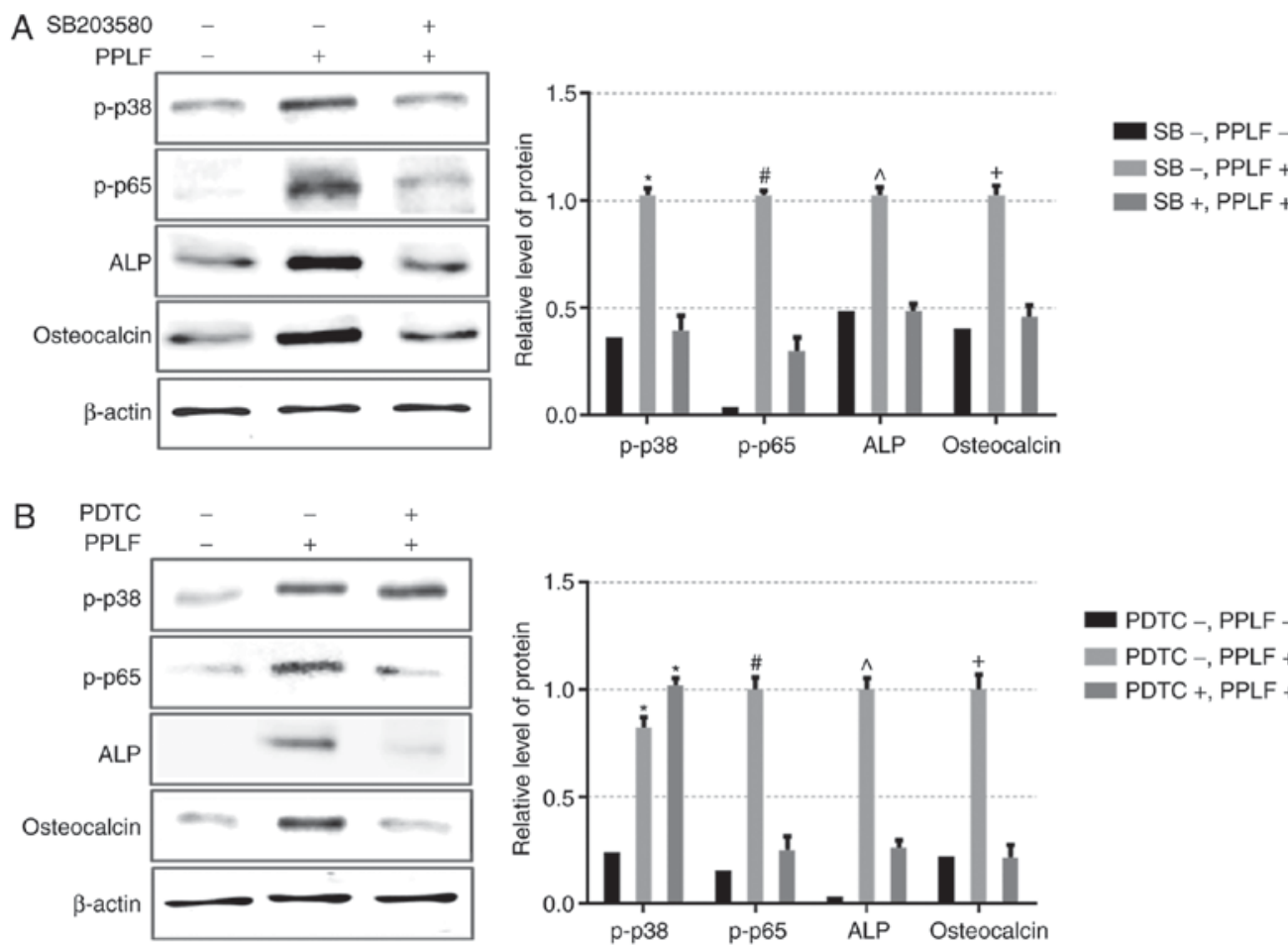

PDTC -, PPLF -

PDTC-, PPLF +

C PDTC +, PPLF +

Figure 6. Effect of the selective inhibitors of p38, (A) SB203580, and p65, (B) PDTC, on osteoblastic differentiation. MG-63 cells were treated with PPLF $(50 \mu \mathrm{M})$ and assessed for the levels of p-p38 and p-p65, ALP and osteocalcin with SB203580 $(20 \mu \mathrm{M})$ or PDTC $(10 \mu \mathrm{M})$. The results were normalized to $\beta$-actin. " $\mathrm{P}<0.05$ vs. p-p38 control (PPLF-); ${ }^{\sharp} \mathrm{P}<0.05$ vs. p-p65 control. (PPLF-); ${ }^{\wedge} \mathrm{P}<0.05$ vs. ALP control (PPLF-); ${ }^{+} \mathrm{P}<0.05$ vs. osteocalcin control (PPLF-). PPLF, peptide of Pavlova lutheri fermentation; ALP, alkaline phosphatase; PDTC, pyrrolidine dithiocarbamate; p-, phosphorylated. 
results suggest that PPLF induces the expression of the early markers of osteoblastic differentiation in MG-63 cells.

PPLF induces ALP and OCN expression via $388 / p 65$ pathway. To determine the mechanism of the PPLF effect on differentiation in MG-63 cells, the phosphorylation levels of MAPK pathway (p38, ERK1/2, Jun) and NF- $\mathrm{B}$ (p65) which are known to control ALP and OCN expression and are involved in osteoblastic differentiation were examined $(8,10,18)$. As shown in Fig. 5, p-p38 and p-p65 exhibited a significant increment by PPLF at 20 and $50 \mu \mathrm{M}(\mathrm{P}<0.05)$, however $\mathrm{p}-\mathrm{ERK} 1 / 2$ and p-Jun did not show any change with PPLF treatment. The result suggests that PPLF treatment activates $\mathrm{p} 38 / \mathrm{p} 65$ signaling pathway. To examine whether the p38/p65 phosphorylation by PPLF treatment was connected to the expression of ALP and OCN, we assessed the expression of ALP and OCN in the cells treated PPLF $(50 \mu \mathrm{M})$ when pre-treated with $\mathrm{p} 38$ inhibitor SB203580 $(20 \mu \mathrm{M})$ or $\mathrm{NF}-\kappa \mathrm{B}$ inhibitor PDTC $(10 \mu \mathrm{M})$. Pre-treatment with SB203580 inhibited both p38 and p65 phosphorylation levels and resulted in a decrease in the expression of ALP and OCN (Fig. 6A). We also observed the same result on ALP and OCN expression by PDTC treatment, however p38 phosphorylation showed no-significant change compared to PPLF treatment suggesting that p38 is upstream of p65 (Fig. 6B). These data suggest that treatment with PPLF induces ALP and OCN expression via p38/p65 signaling pathway in MG-63 cells.

\section{Discussion}

Microbial fermentation by proteolytic action can produce small molecule peptides from the parent proteins with various activities. These peptides have been reported to have role as part of dietary proteins in controlling and influencing health $(3,20)$. In the present study, we have shown that the fermented of microalgae $P$.lutheri (by H.polymorpha) causes a significant elevation in differentiation at a concentration of 50 and $100 \mu \mathrm{g} / \mathrm{ml}$ in human osteoblastic MG-63 cells compared to the cells treated with non-fermented P. lutheri (Fig. 1B). Following this, we fractionalized the fermented $P$. lutheri using chromatography separation and measured the ALP activity of each separated fraction to purify the active responsible peptide (Fig. 2). Through ESI/MS spectroscopy, the purified peptide (PPLF) was sequenced as Glu-Pro-Gln-Trp-Phe-Leu (MW 908.9) which has rich-hydrophobic amino acids including one acidic residue (Glu), four basic residues (Pro, Trp, Phe, Leu), and one aromatic residue (Trp). High levels of hydrophobic and aromatic amino acids have been shown to rejuvenate cellular activity, cell differentiation and metabolism (21).

Subsequently, we showed that PPLF significantly promoted ALP release and mineralization concentration-dependently and further observed an increase in the protein levels of ALP and OCN by PPLF treatment (Figs. 3 and 4). ALP, OCN and mineralization are specific markers of differentiation that are known to be involved in differentiation of mature osteoblasts and induced by p38 MAPK and p65 (a subunit of NF-кB) (22). p38/p65 are widely conserved family of serine threonine protein kinases implicated in several cellular programs such as cell proliferation, calcification, and apoptosis (23). A number of studies have reported that p38 and p65 pathways are required in osteoblast differentiation and act downstream of BMP receptors and play important roles in osteoblast differentiation and bone remodeling $(16,24,25)$. Indeed, p38 pathway has been found to contribute to bone formation by phosphorylating the p65 subunit of $\mathrm{NF}-\kappa \mathrm{B}$ transcription complex and thus increasing $N F-\kappa B$ transcriptional activity (23). In this study, we showed that PPLF increased the activation of p38 and p65 whereas did not have any effect on the ERK1/2 and Jun phosphorylation (Fig. 5). Furthermore, we demonstrated that selective inhibitors of p38 and p65 significantly inhibited the expression of differentiation specific markers (ALP and OCN) indicating that PPLF induces osteoblastic differentiation in MG-63 cells by triggering activation of p38/p65 signaling pathway (Fig. 6).

Our data shows that fermented $P$. lutheri promotes differentiation of MG-63 cells and the peptide PPLF which was purified from the fermented $P$. luther $i$ is responsible for the increased differentiation in MG-63 cells through p38/p65 activation. Our work shows the potential of the fermented $P$. lutheri as an inducer of osteoblast differentiation and further suggests PPLF peptide as a likely candidate for the treatment of bone loss and promotion of bone health.

\section{Acknowledgements}

The present study was supported by a grant from the Marine Biotechnology Program (20150220) funded by the Ministry of Oceans and Fisheries, Republic of Korea.

\section{References}

1. Steinkraus KH: Fermentations in world food processing. Compr Rev Food Sci Food Saf 1: 23-32, 2002.

2. Kudoh Y, Matsuda S, Igoshi K and Oki T: Antioxidative peptide from milk fermented with Lactobacillus delbrueckii subsp bulgaricus IFO13953. J Jpn Soc Food Sci 48: 44-50, 2001.

3. Korhonen $\mathrm{H}$ and Pihlanto A: Bioactive peptides: Production and functionality. Int Dairy J 16: 945-960, 2006.

4. Korhonen $\mathrm{H}$ and Pihlanto A: Bioactive peptides from food proteins. In: Handbook of Food Products Manufacturing: Health, Meat, Milk, Poultry, Seafood and Vegetables. John Wiley \& Sons, Inc., Hoboken, NJ, pp5-37, 2007.

5. Gupta A, Mann B, Kumar R and Sangwan RB: Antioxidant activity of cheddar cheeses at different stages of ripening. Int $\mathrm{J}$ Dairy Technol 62: 339-347, 2009.

6. Spolaore P, Joannis-Cassan C, Duran E and Isambert A: Commercial applications of microalgae. J Biosci Bioeng 101: 87-96, 2006.

7. Qian ZJ, Jung WK, Kang KH, Ryu B, Kim SK, Je JY, Heo SJ, Oh C, Kang DH, Park WS and Choi IW: In vitro antioxidant activities of the fermented marine microalga Pavlova lutheri (haptophyta) with the yeast Hansenula polymorpha. J Phycol 48: 475-482, 2012.

8. Xiao Y, Haase H, Young WG and Bartold PM: Development and transplantation of a mineralized matrix formed by osteoblasts in vitro for bone regeneration. Cell Transplant 13: 15-25, 2004.

9. de Crombrugghe B, Lefebvre V and Nakashima K: Regulatory mechanisms in the pathways of cartilage and bone formation. Curr Opin Cell Biol 13: 721-727, 2001.

10. Teitelbaum SL: Bone resorption by osteoclasts. Science 289: 1504-1508, 2000.

11. Ducy P, Schinke T and Karsenty G: The osteoblast: A sophisticated fibroblast under central surveillance. Science 289: 1501-1504, 2000.

12. Day TF, Guo X, Garrett-Beal L and Yang Y: Wnt/beta-catenin signaling in mesenchymal progenitors controls osteoblast and chondrocyte differentiation during vertebrate skeletogenesis. Dev Cell 8: 739-750, 2005. 
13. Greenblatt MB, Shim JH and Glimcher LH: Mitogen-activated protein kinase pathways in osteoblasts. Annu Rev Cell Dev Biol 29: 63-79, 2013

14. Thouverey $\mathrm{C}$ and Caverzasio J: The $\mathrm{p} 38 \alpha$ MAPK positively regulates osteoblast function and postnatal bone acquisition. Cell Mol Life Sci 69: 3115-3125, 2012.

15. Danciu TE, Adam RM, Naruse K, Freeman MR and Hauschka PV: Calcium regulates the PI3K-Akt pathway in stretched osteoblasts. Febs Lett 536: 193-197, 2003.

16. Peverali FA, Basdra EK and Papavassiliou AG: Stretch-mediated activation of selective MAPK subtypes and potentiation of AP-1 binding in human osteoblastic cells. Mol Med 7: 68-78, 2001.

17. GranetC,Boutahar N, Vico L, Alexandre C and Lafage-Proust MH: MAPK and SRC-kinases control EGR-1 and NF-kappa B inductions by changes in mechanical environment in osteoblasts. Biochem Biophys Res Commun 284: 622-631, 2001.

18. Eichner A, Brock J, Heldin CH and Souchelnytskyi S: Bone morphogenetic protein-7 (OP1) and transforming growth factor-beta 1 modulate 1,25(OH)2-vitamin D3-induced differentiation of human osteoblasts. Exp Cell Res 275: 132-142, 2002.

19. Ryu B, Li Y, Qian ZJ, Kim MM and Kim SK: Differentiation of human osteosarcoma cells by isolated phlorotannins is subtly linked to COX-2, iNOS, MMPs and MAPK signaling: Implication for chronic articular disease. Chem Biol Interact 179 192-201, 2009
20. Moller NP, Scholz-Ahrens KE, Roos N and Schrezenmeir J: Bioactive peptides and proteins from foods: Indication for health effects. Eur J Nutr 47: 171-182, 2008.

21. Eriksson LS: Administration of aspartate to patients with liver-cirrhosis. Clin Nutr 4: 88-96, 1985.

22. Ryu B, Qian ZJ and Kim SK: Purification of a peptide from seahorse, that inhibits TPA-induced MMP, iNOS and COX-2 expression through MAPK and NF-kappaB activation, and induces human osteoblastic and chondrocytic differentiation. Chem Biol Interact 184: 413-422, 2010.

23. Huang H, Ryu J, Ha J, Chang EJ, Kim HJ, Kim HM, Kitamura T, Lee ZH and Kim HH: Osteoclast differentiation requires TAK1 and MKK6 for NFATc1 induction and NF-kappaB transactivation by RANKL. Cell death Differ 13: 1879-1891, 2006.

24. Villa I, Melzi R, Pagani F, Ravasi F, Rubinacci A and Guidobono F: Effects of calcitonin gene-related peptide and amylin on human osteoblast-like cells proliferation. Eur J Pharmacol 409: 273-278, 2000.

25. Wang L, Li JY, Zhang XZ, Liu L, Wan ZM, Li RX and Guo Y: Involvement of $\mathrm{p} 38 \mathrm{MAPK} / \mathrm{NF}-\mathrm{\kappa B}$ signaling pathways in osteoblasts differentiation in response to mechanical stretch. Ann Biomed Eng 40: 1884-1894, 2012. 